\title{
Parallel Machine Scheduling for Minimizing Flowtime: Case Study at Aircraft Company $X$ Turnin and Milling Departments
}

\author{
Asep Anwar*, Didit Damur Rochman \\ Department of Industrial Engineering, Widyatama University, Indonesia
}

Copyright $\bigcirc 2019$ by authors, all rights reserved. Authors agree that this article remains permanently open access under the terms of the Creative Commons Attribution License 4.0 International License

\begin{abstract}
Company $X$ in 2017 has a delay in the Turning and Milling department of $58 \%$ of the total order of 2,334 . The actual condition is the number of machines used, namely $5 \mathrm{CNC}$ machines with a production capacity of 230.4 hours / week and the number of work orders from 2013-2018 that must be done is 2767,458 hours. The delay was due to the absence of an appropriate engine scheduling system. Modeling uses mathematical models and runs using lingo software. The results of calculations using LINGO for mathematical models are 14,274 hours with a calculation time of 17 minutes 55 seconds.
\end{abstract}

Keywords Parallel Machine Scheduling

\section{Introduction}

Machine scheduling is parts of execution production planning, needs to pay attention to keep synchronize between planning and execution, and the manufacturing performance depends on it. The most problem arise in some manufacture industry where order release to the shop floor only listed partial information such as job to get work done without specified work sequence detail. This happen at turning and milling departments at company $\mathrm{X}$ that produce aircraft spare parts, moreover employing parallel machine scheduling cannot give exact solution because there aren't efficient algorithm exist to solve every problem in parallel machine scheduling (Makotof, 2001; El-Gali,2018). Categorizing algorithm as $\mathrm{P}$ or NP give more understanding that some machine scheduling algorithm can give solution or not, as suggested by Chen and Sin (1990) study on parallel machine scheduling algorithm should more focused on heuristic and exponential algorithm.

Using package software to solve specific industry machine scheduling more seen as hit and miss solution. Generalization problem without considering practical limitation at shop floor from human skill, machine and environment, job and product characteristics, and planning method will lead to manager frustration and abandonment software, than back to practical approach using pencil and spreadsheet (Rodammer and White, 1988; El-Shorbagy, Mousa \& Farag 2017; Hajirahimova \& Aybeniz, 2018; Mostofi \& Erfanian, 2018). Unique characteristic machine scheduling at different company leads to development algorithm for specific needs and characteristics. These make machine scheduling as dynamic theme follow development of company to fulfill customer requirements and technological change.

At company X who employ off the shelf ERP system, specifically at turning and milling department has recorded $58 \%$ late job in 2017 , to reduce backlog machine utilization should increase as high as $1504 \%$. That something unbelievable happened, and will continue to happen if there aren't improved on machine scheduling. Currently they employ simple sequencing rules FCFS for 5 parallel machine for every order release to shop floor. Preliminary improvement that departments take is renegotiating all backlog job to future date and improvement on order workflow to shop floor so machine operators not take their own decision on which job/order they work as effort to get real shop floor performance in the future.

At the backend the machine scheduling algorithm have to be employed for better scheduling with match characteristics with turning and milling departments. According to Halim et al (1994) states that flowtime is the length of time required when production from the beginning of the part to completion in accordance with the dateline. Minimizing flowtime makes production activities in the company will be more controlled in the production process so that it can reduce the delay in time requests from consumers. This paper will discussed development of machine scheduling algorithm for that purpose. 


\section{Problem Formulation}

Turning and milling department have 5 CNC machine identical type and year made, for every order release from ERP as job $\mathrm{J}=1,2, \ldots, \mathrm{N}$ with different consumer, due dates $\left(T_{j}\right)$ and processing time $\left(p_{j}\right)$. These jobs will be assigned to parallel CNC machine $(\mathrm{m})$. Basic rules, that job will be assigned to idle machine or after finished other job or after completion time from previous job $\left(C_{j-1, m}\right)$. To calculate flowtime $\left(\mathrm{F}_{\mathrm{jm}}\right)$ from ordering time, assumed that raw material always available. To illustrate the problem as describe before in Figure 2.

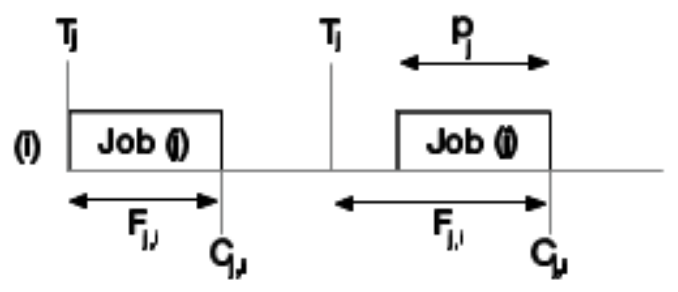

Figure 1. Job, Flow time and Completion Time

We developed mathematical model to solve machine scheduling problem as described before with notation as follow:

$\mathrm{j}=$ Job before assigned to machine $\mathrm{i}$.

$\mathrm{w}=\mathrm{Job} \mathrm{j}$ assigned to machine $\mathrm{i}$.

$\mathrm{m}=$ Machine

$\mathrm{p}_{\mathrm{j}}=$ Job j process time

$s_{j}=$ Job j start time or job j order time.

$\mathrm{T}_{1}=$ job j start time according to schedule

$\mathrm{C}_{\mathrm{ji}}=$ Job $\mathrm{j}$ completion time on machine $\mathrm{i}$

$\mathrm{F}_{\mathrm{ji}}=$ job $\mathrm{j}$ flowtime on machine $\mathrm{i}$

$\mathrm{n}=$ Number of job $\mathrm{j}$

$\mathrm{X}_{\mathrm{ji}}\left\{\begin{array}{l}=1 \text { if job } \mathrm{j} \text { assigned to machine } \mathrm{i}, \\ =0 \text { if job } \mathrm{j} \text { not assigned to machine } \mathrm{i}\end{array}\right.$

Performance measurement for this machine scheduling is focused to minimized flow time, so goal function of algorithm

$$
\operatorname{Min}\left(\sum_{m=1}^{M} \sum_{j=1}^{J} F_{j m}\right) / n \quad \begin{array}{r}
\text { for } j=1 \ldots J \\
m=1 \ldots M
\end{array}
$$

With constraint

$$
\begin{aligned}
& \sum^{I} X_{j m}=1 \quad \text { for } j=1 \ldots J \\
& m=1 . . . M \\
& \begin{array}{c}
\text { for } j=1 \ldots J, \\
s_{j m} \geq T_{j} \times X_{j m} \quad 1 \ldots M
\end{array} \\
& s_{1, m}=0 \quad \text { for } m=1 \ldots M \text {, } \\
& s_{j m} \geq C_{w m} \quad \text { for } j=1 \ldots J \\
& w<j
\end{aligned}
$$

$$
\begin{gathered}
C_{j m}=\left(s_{j m}+p_{j}\right) \times X_{j m} \quad \begin{array}{c}
\text { or } j=1 \ldots J, \\
m=1 \ldots M
\end{array} \\
F_{j m}=C_{j m}-\left(T_{j} \times X_{j m}\right) \quad \begin{array}{c}
\text { for } j=1 \ldots J, \\
m=1 \ldots M
\end{array} \\
C_{j m}, F_{j m}, s_{j, m} \geq 0 \\
\text { for } j=1 \ldots J, \\
m=1 \ldots M
\end{gathered}
$$

Equation (2) to ensure that job $\mathrm{j}$ will be assigned on single machine $\mathrm{m}$, and (3) are constrain that start time job $\mathrm{j}$ bigger than assigned start time or order time. While equation (4) determined if $\mathrm{j}=1$ than job start time at $\mathrm{t}=0$, equation (5) to constrained that start time job $\mathrm{j}$ has bigger than completion time job before. Equation (6) to calculate completion time job j on machine I, meanwhile equation (7) to assign job j flow time on machine $m$, and equation (8) to ensure all variable non negative value.

\section{Results and Discussion}

Implementing model to empirical data that we obtain from company (Table 1), we focused only 50 orders as jobs to schedule. We limit number job because constrained computation power that currently we have.

Table 1. Job Data

\begin{tabular}{|c|c|c|c|c|c|c|c|}
\hline No & Order & $\begin{array}{c}\text { Start Date } \\
(\boldsymbol{H})\end{array}$ & $\begin{array}{c}\text { Process } \\
\text { Time } \\
(\boldsymbol{H})\end{array}$ & No & Order & $\begin{array}{c}\text { Start } \\
\text { Date } \\
(\boldsymbol{H})\end{array}$ & $\begin{array}{c}\text { Process } \\
\text { Time } \\
(\boldsymbol{H})\end{array}$ \\
\hline 1 & 20222294 & 0 & 12,06 & 26 & 20407414 & 112 & 2,58 \\
\hline 2 & 20230540 & 0 & 14,60 & 27 & 20407425 & 112 & 7,79 \\
\hline 3 & 20283227 & 0 & 3,60 & 28 & 20407426 & 112 & 7,79 \\
\hline 4 & 20290965 & 0 & 4,53 & 29 & 20397665 & 120 & 15,50 \\
\hline 5 & 20292143 & 0 & 5,72 & 30 & 20356385 & 128 & 10,83 \\
\hline 6 & 20299748 & 0 & 0,21 & 31 & 20395304 & 128 & 3,88 \\
\hline 7 & 20300875 & 0 & 1,55 & 32 & 20407016 & 136 & 38,23 \\
\hline 8 & 20301079 & 0 & 1,49 & 33 & 20409240 & 168 & 67,24 \\
\hline 9 & 20303774 & 0 & 1,43 & 34 & 20410184 & 184 & 20,32 \\
\hline 10 & 20307309 & 0 & 3,78 & 35 & 20409640 & 192 & 13,22 \\
\hline 11 & 20312361 & 0 & 2,01 & 36 & 20406228 & 224 & 1,80 \\
\hline 12 & 20320214 & 0 & 1,93 & 37 & 20328904 & 232 & 2,35 \\
\hline 13 & 20329762 & 0 & 2,41 & 38 & 20409154 & 232 & 1,30 \\
\hline 14 & 20344687 & 0 & 2,93 & 39 & 20410615 & 248 & 9,49 \\
\hline 15 & 20395250 & 0 & 11,53 & 40 & 20401155 & 272 & 1,90 \\
\hline 16 & 20401023 & 0 & 0,81 & 41 & 20401383 & 280 & 6,00 \\
\hline 17 & 20402047 & 0 & 2,93 & 42 & 20390242 & 296 & 1,41 \\
\hline 18 & 20394864 & 48 & 2,76 & 43 & 20407204 & 296 & 1,78 \\
\hline 19 & 20400751 & 64 & 12,56 & 44 & 20409078 & 296 & 7,89 \\
\hline 20 & 20400228 & 72 & 10,28 & 45 & 20401586 & 304 & 43,11 \\
\hline 21 & 20406574 & 88 & 2,90 & 46 & 20407072 & 328 & 3,62 \\
\hline 22 & 20406575 & 88 & 2,00 & 47 & 20409212 & 328 & 1,81 \\
\hline 23 & 20372454 & 104 & 1,71 & 48 & 20413475 & 336 & 0,16 \\
\hline 24 & 20401037 & 104 & 1,90 & 49 & 20399057 & 464 & 1,99 \\
\hline 25 & 20395316 & 112 & 2,80 & 50 & 20390667 & 496 & 2,26 \\
\hline
\end{tabular}

To obtained solution, we use lingo software for linear programming optimization and creating small lingo script (figure 2) will be run on computer with core i5 processor and 4GB RAM. 


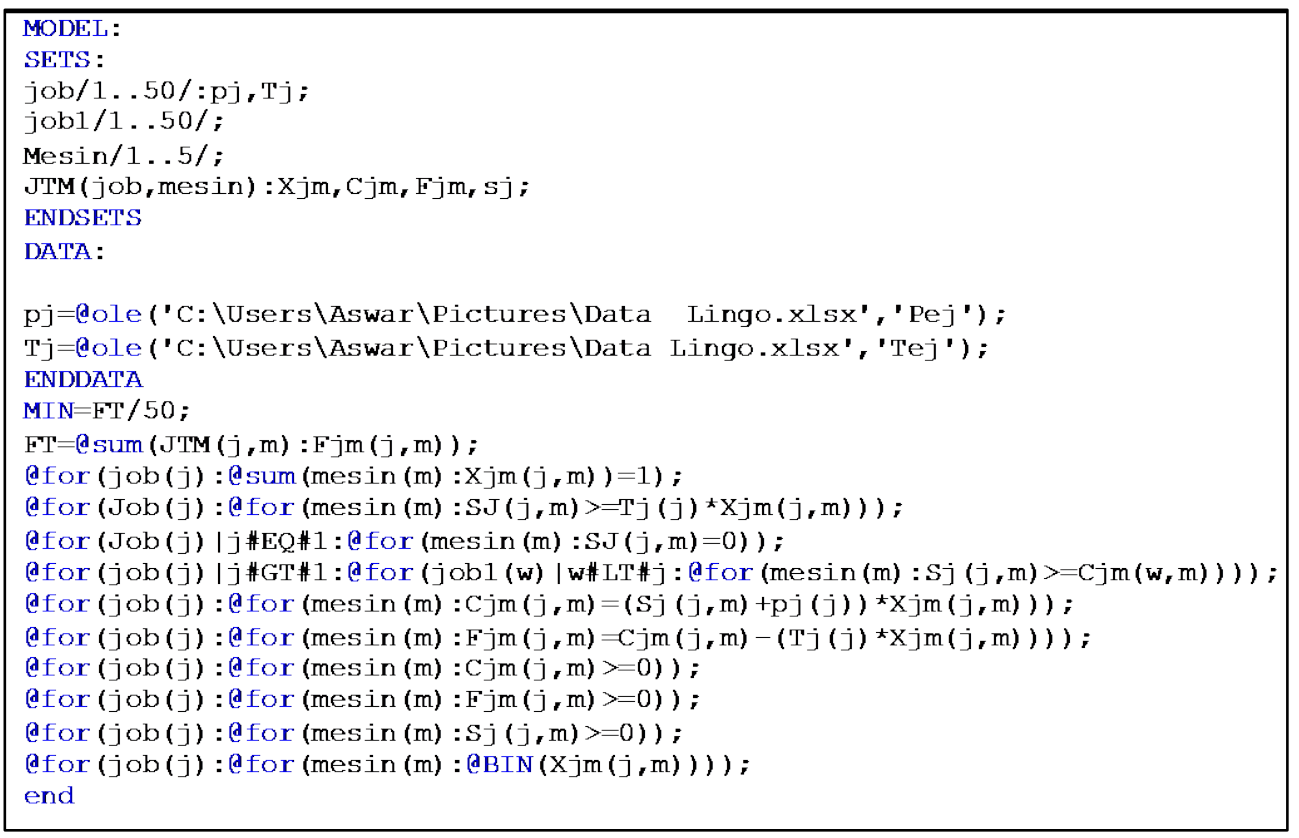

Figure 2. Lingo Model

We obtained solution took 17 minutes and 55 second and not detected as NP hard problem (Figure 3), solution optimal found after 14 minutes with global optimal state.

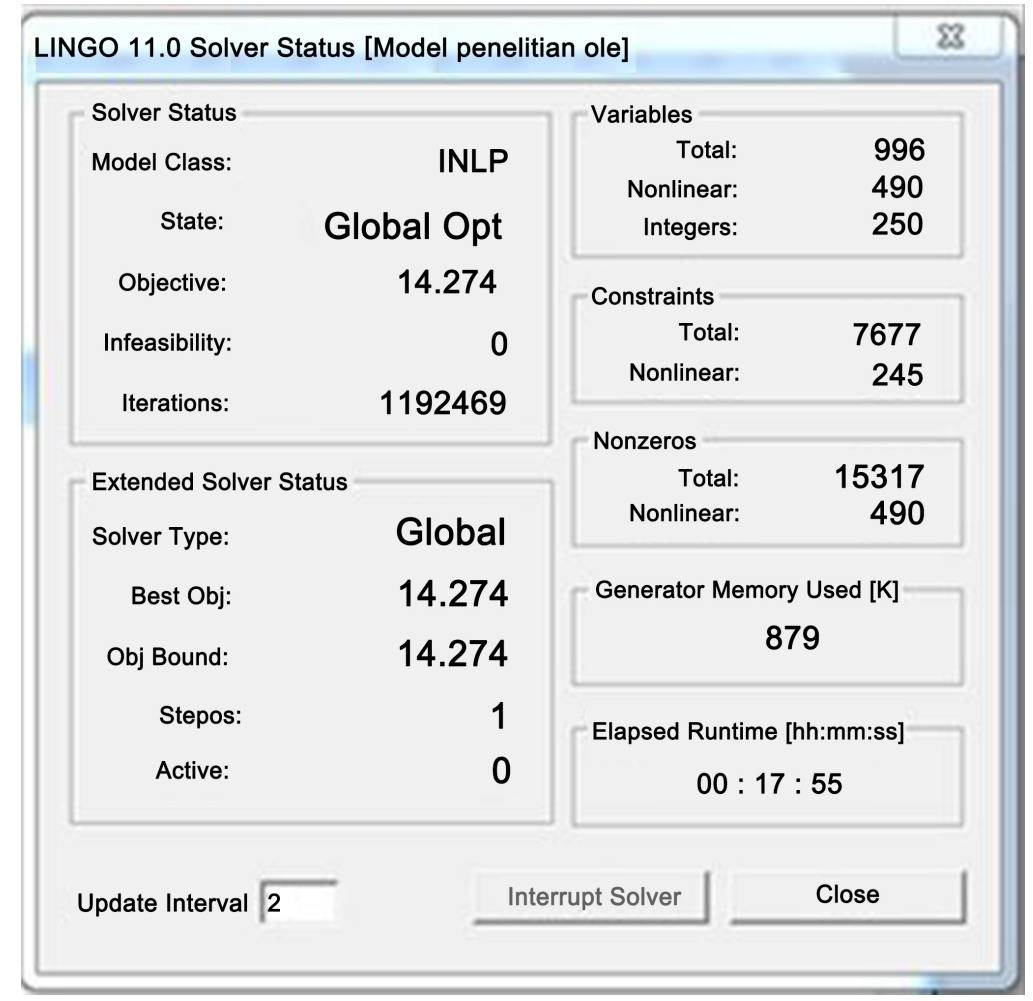

Figure 3. Lingo Run Time

Job assignment from lingo computation was described at table 2 show each job assignment on machine and maximum completion time for all job to be finished. Makespan to be finished all 50 jobs are 498.26 hours. The result for average flowtime is 14,274 hours. 
Table 2. Job Assignment and Max Completion Time

\begin{tabular}{|c|l|c|}
\hline Machine & \multicolumn{1}{|c|}{ Job } & $\begin{array}{c}\text { Max Completion Time } \\
\text { (hour) }\end{array}$ \\
\hline 1 & $1,18,19,20,21,22,23,24,25,26,30,34,36,37$, & 465.99 \\
& $38,39,40,41,44,46,47,48,49$, & \\
\hline 2 & $\begin{array}{l}3,4,5,6,7,8,9,10,11,12,13,14,15,16,17,28,3 \\
5,43,45\end{array}$ & 347.11 \\
\hline 3 & $2,33,50$, & 498.26 \\
\hline 4 & $27,31,32,42$ & 297.41 \\
\hline 5 & 29 & 135.5 \\
\hline
\end{tabular}

\section{Conclusions}

Using this model to complete 50 jobs in the company for shows that if the company is doing a good scheduling, there will be no more jobs that are late for processing and even the engine is idle especially for engine 5 . the results of this average flowtime indicate that the average waiting time for completing orders from consumers is 14,274 hours.

Future research can be done by changing the research method with a heuristic method which can then be compared to the results and time of calculation needed so that which method is more relevant to be implemented in the field.

\section{REFERENCE}

[1] Cheng, T. C. E., \& Sin, C. C. S. (1990). A state-of-the-art review of parallel-machine scheduling research. European Journal of Operational Research, 47(3), 271-292.

[2] El-Gali, Z. I. (2018). Evaluation of Some Plant Extracts and Powders in Control of Bean Damping-Off By Sclerotinia Sclerotiorum. Agriculture and Food Sciences Research, 5(1), 47-51.

[3] El-Shorbagy, M. A., Mousa, A. A., \& Farag, M. (2017). Solving Nonlinear Single-Unit Commitment Problem by Genetic Algorithm Based Clustering Technique. Review of Computer Engineering Research, 4(1), 11-29.

[4] Halim, Abdul Hakim, Shigeji Miyazaki, and Hiroshi Ohta. "Batch-scheduling problems to minimize actual flow times of parts through the shop under JIT environment." European Journal of Operational Research 72.3 (1994): 529-544.

[5] Mokotoff, E. (2001). Parallel machine scheduling problems: A survey. Asia-Pacific Journal of Operational Research, $18(2), 193$

[6] Rodammer, F. A., \& White, K. P. (1988). A recent survey of production scheduling. IEEE transactions on systems, man, and cybernetics, 18(6), 841-851.

[7] Hajirahimova, M., \& Aybeniz, A. (2018). Current Approaches in Prediction of PVT Properties of Reservoir Oils. Review of Information Engineering and Applications, 5(2), 31-40.
[8] Mostofi, A., \& Erfanian, H. (2018). Multi-Shuttle Automated Storage and Retrieval System. Review of Industrial Engineering Letters, 4(1), 12-20. 